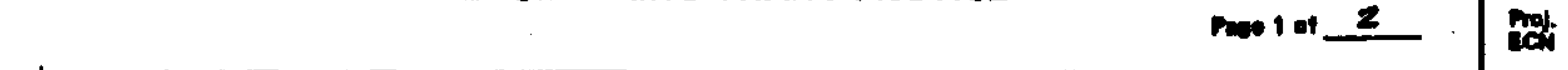

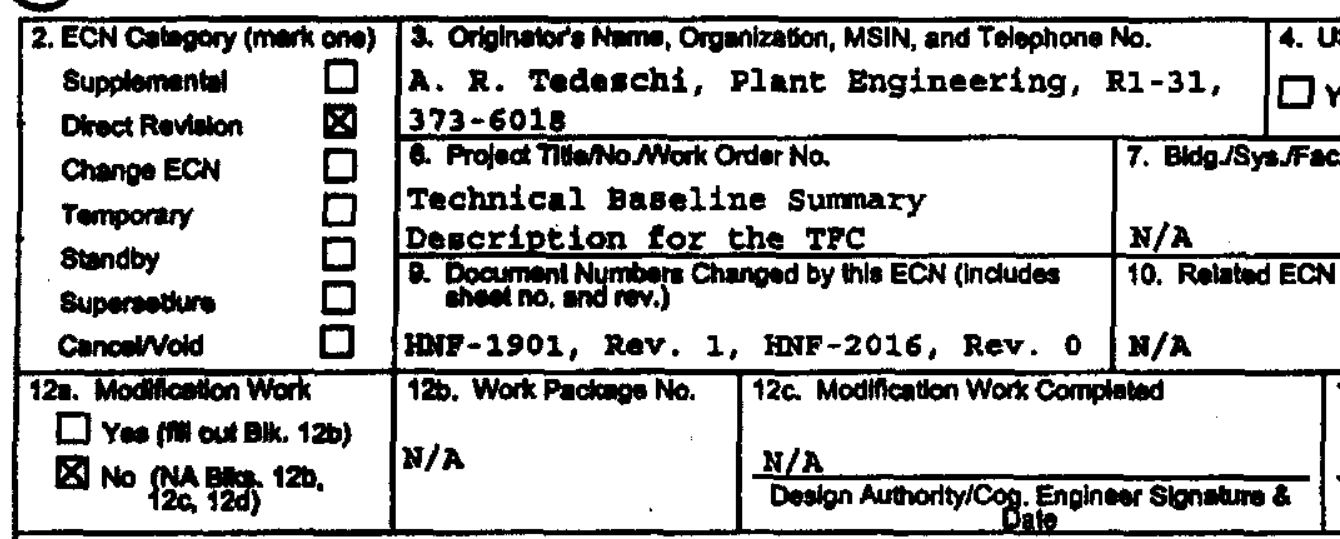

13. Description of Change

13b. Desion Baseline Document? $\square$ ras $\nabla$ No

1) New technical baseline definitions and resulting date were incorporated.

2) Mission ncope discuasilon wa minimized and references to upper-level documents were added.

3) Technical information and references were updated.

4) This document also bupercedea HNP-2016, "TWRs Technical Baseline Summary Degcription"

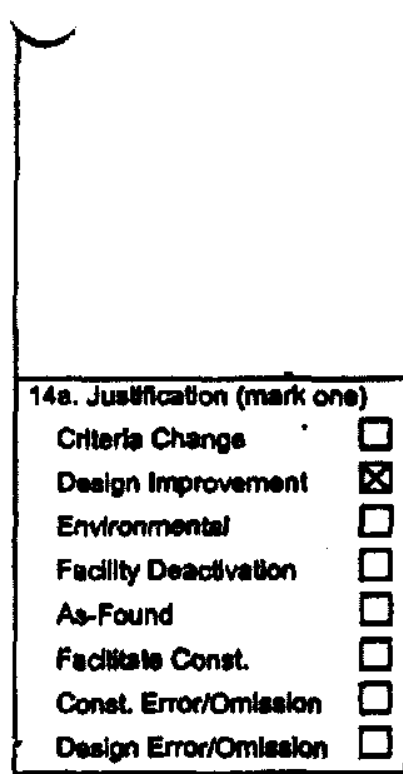

15. Distrbution (inctude nams, MSIN, and no. of copias)

-See Attached Distribution Iit 14b. Justicalion Datalls

UPDATE/REVISION OF BUEJECT DOCUMENT (HNF-1901)

The mubject document contains sumary Information for the technical baseline and mall be updated periodically as new information becomes available. It reflects the most current plans, congistent with the retrleval and dieposal mipsion.

$$
1
$$

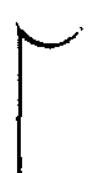

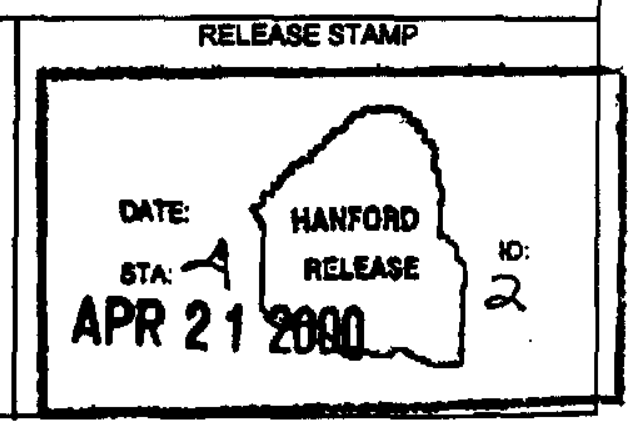

A.7800013-1 


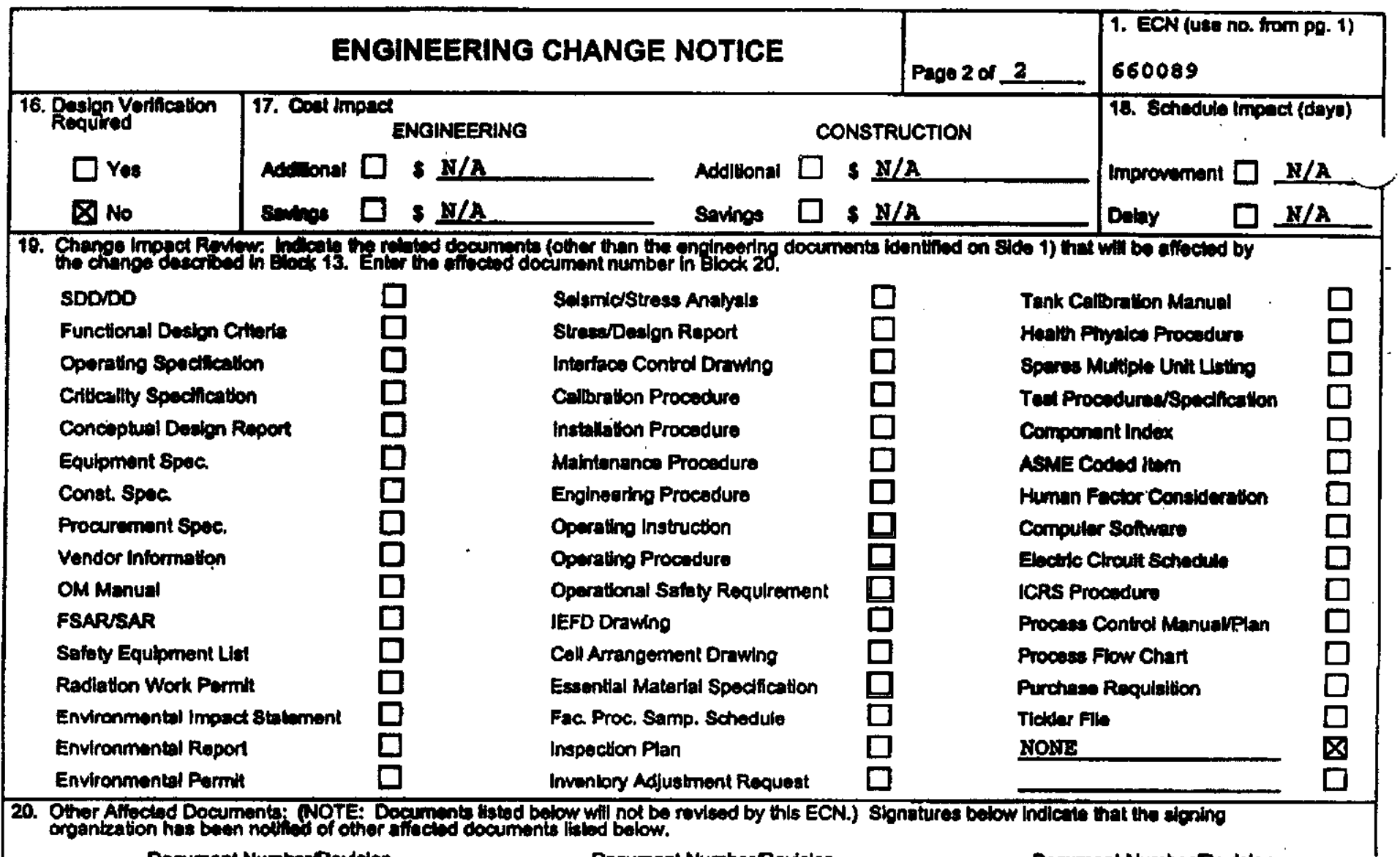
$\mathrm{N} / \mathrm{A}$
Document Numbar/Rovion
Document Number/Revision
Document NumberiRevision
N/A
$\mathbf{N} / \mathbf{A}$.

N/A
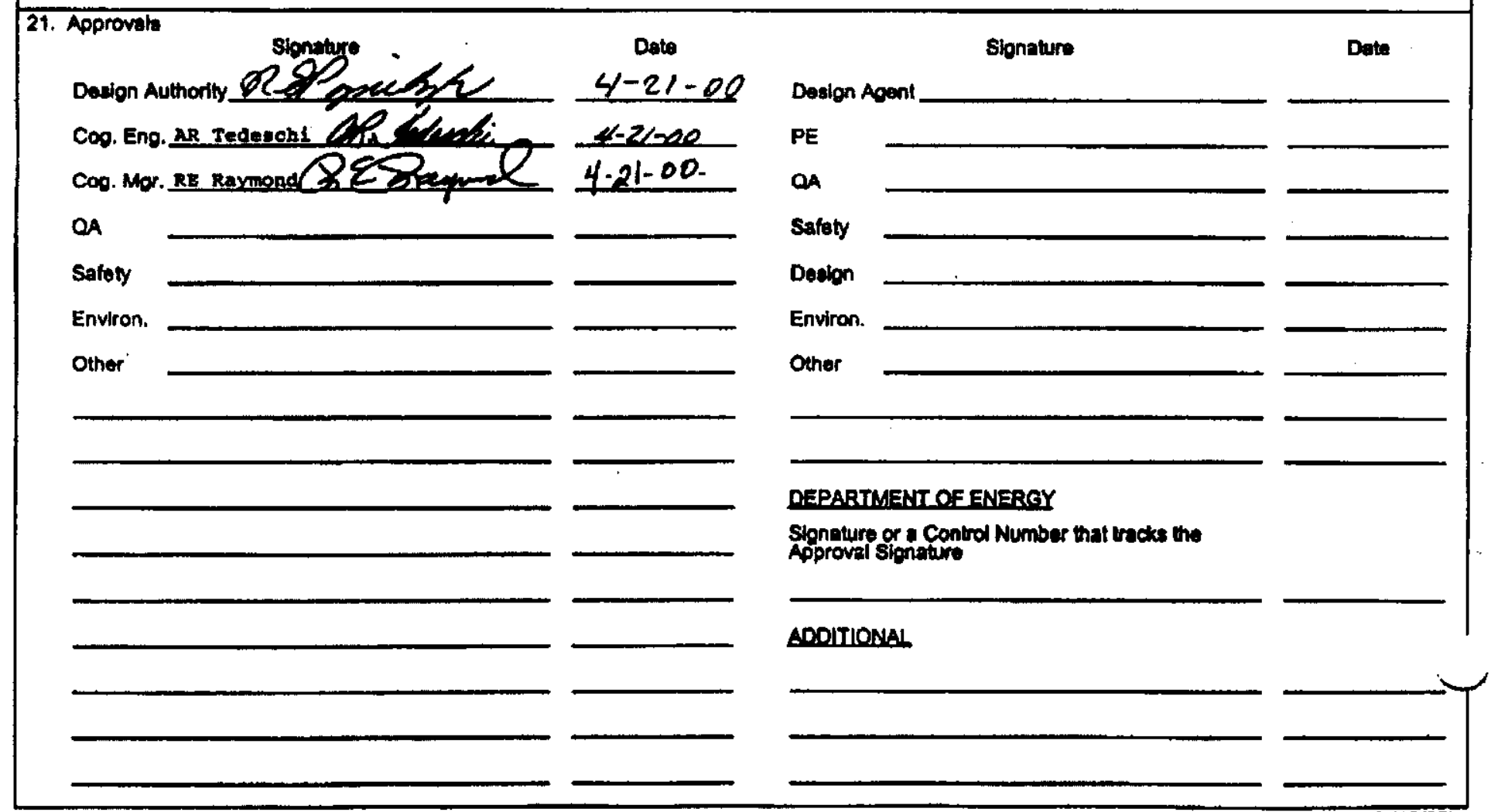

A.7900-013-3(10/07) 


\title{
Tank Waste Remediation System Technical Baseline Summary Description
}

\author{
A. R. Tedesohi \\ CH2M HILL Hanford Group, Inc. \\ Rlchland, WA 99352 \\ U.S. Department of Energy Contract DE-AC06-99RL14047 \\ EDT/ECN: ECN $660089 \quad$ UC: 2030 \\ Cost Center: 71300 Charge Code: 108521/AA3 \\ B\&R Code: Ew310010 Total Pages: 2 \\ Key Words: technical baseline, tank farm, TWRS
}

Abstract: This revision notes the supersedure of the subject document by concurrent issuance of HNF-1901 "Technical Baseline Sumary Description for the Tank Farm Contractor", Revision 2. Safe storage mission technical baseline information was absorbed by the new revision of HNE-1901.

TRADEMARK DISCLAMER. Refarence herein to eny specific commerclal product, procesa, or sarvlce by trade name,

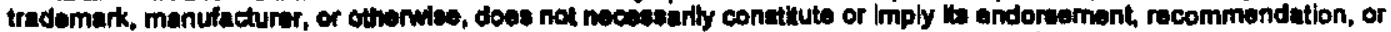
favoring by the United stales covernment or eny ueney thereof or lis contractors or subcontractors.

Printed in the United states of Amorlea. To obtahn coples of thls document, contect: Document Control Services, P.O. Box 950, Mailetop H3-08, Richland WA 99352, Phono (509) 372-2420; Fax (609) 376-4989.
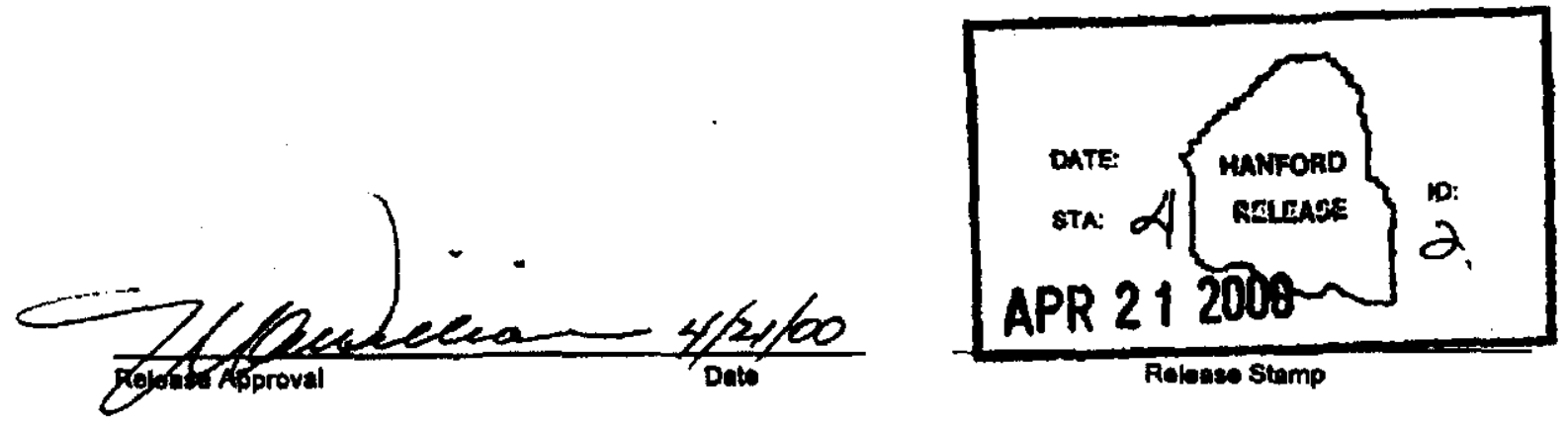

Folowes Stomp

Approved For Public Release 


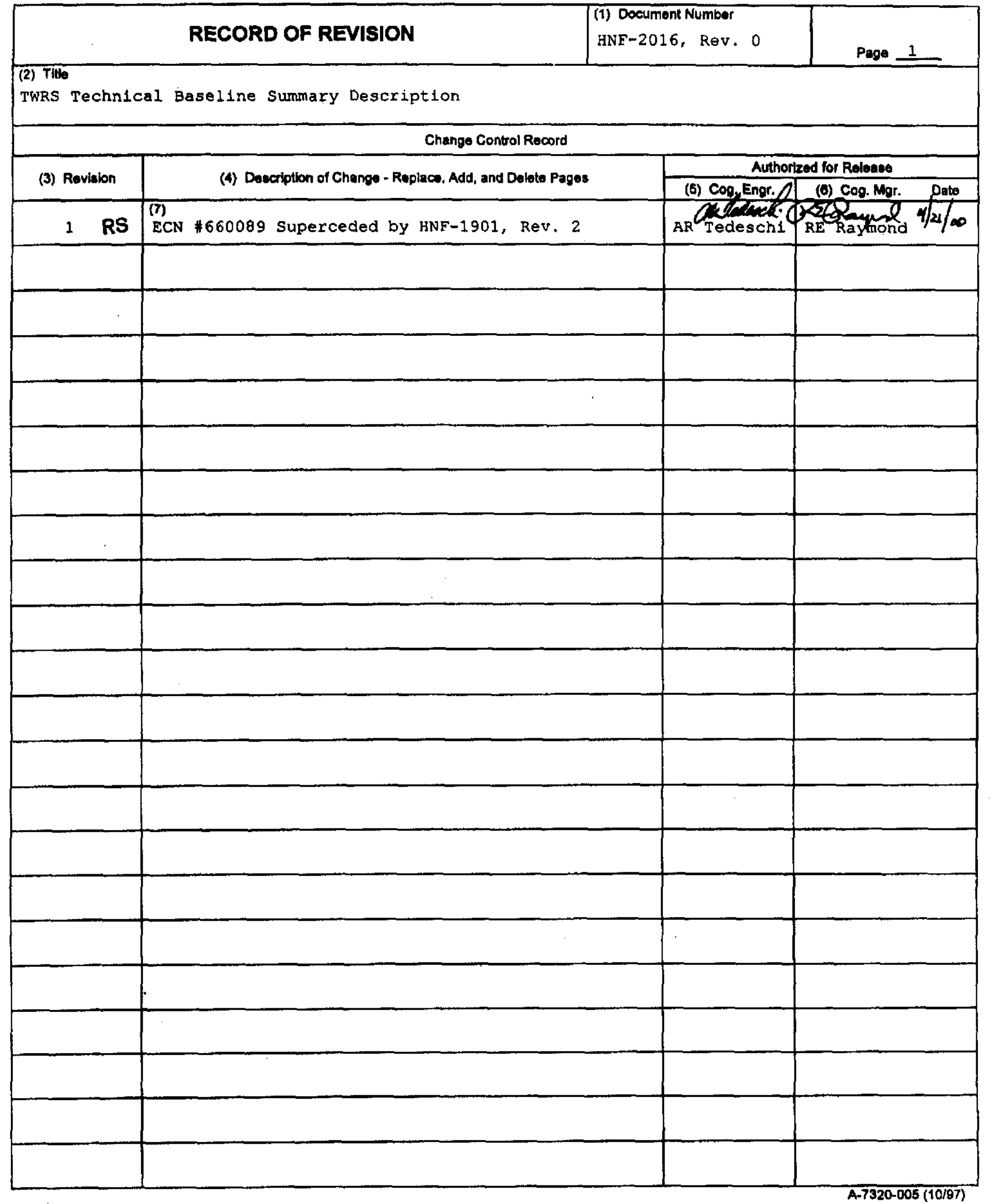

